\title{
REMASTERING LIVE USB UNTUK "LAMP" PADA FAKULTAS SAINS DAN TEKNOLOGI PALEMBANG
}

\author{
Klaudius Jevanda B.S. \\ Fakultas Sains dan Teknologi, Program Studi Informatika \\ Universitas Katolik Musi Charitas \\ Email: exvans.007@gmail.com
}

\begin{abstract}
ABSTRAK
Penelitian ini bertujuan untuk membuat distribusi Linux bernama Lubuntu yang memfokuskan diri pada desktop yang ringan serta ditujukan untuk menjadi lingkungan web server yang free dalam bentuk live USB. Dimana, penelitian ini menjelaskan tentang desain dan implementasi dari distribusi Linux Lubuntu itu sendiri yang nantinya bisa terus diperbaiki, disempurnakan dan dimungkinkan untuk dimodifikasi serta dipelajari oleh pihak lain. Lubuntu dikembangkan dengan memodifikasi dari Linux Lubuntu 14.04 dari tahap penambahan program, penghapusan program dan konfigurasi sampai pada tahap pembuatan Live USB untuk LAMP (Linux Apache Mysql PHP) menggunakan metode remastering. Hasil dari penelitian ini berupa Live USB yang berisi tool untuk lingkungan web server. Tool utama dalam Live USB diantaranya adalah phpmyadmin, gimp, inkscape, dan bluefish. Keluaran penelitian ini, diharapkan bisa digunakan sebagai sistem operasi dan dikhususkan dalam lingkungan web server yang nyaman untuk dipergunakan dalam proses belajar mengajar pada matakuliah sistem operasi, pemrograman basis web I, dan pemrograman basis web II di Fakultas Sains dan Teknologi Universitas Katolik Musi Charitas palembang.
\end{abstract}

Kata kunci: linux, web server, LAMP, remastering, live usb.

\begin{abstract}
The research aims to make the linux distribution namely Lubuntu that focuses on lightweight desktop environment and to create a free Live USB environment. This research explains the design and implementation the Linux Lubuntu distribution which will be continuously improved, modified, and learned by other. Lubuntu is developed by modifying the Linux Lubuntu 14.04 from addition, elimination, and configuration stages to the making of a Live USB to LAMP (Linux Apache MySQL PHP) by using remastering method stage. The result of the research is a Live USB which contains tools for web server environment. The main tools in this Live USB are phpmyadmin, gimp, inkscape, and bluefish. The output of this research is expected to bu used as an operation system, specifically in a comfortable web server enviroment for the teaching and learning process in operating system course, web-based programming I, and web-based programming II at Fakultas Sains dan Teknologi Universitas Katolik Musi Charitas Palembang.
\end{abstract}

Keywords: linux, web server, LAMP, remastering, live usb.

\section{PENDAHULUAN}

Sekarang ini, perkembangan teknologi informasi dan komunikasi semakin pesat. Pengguna komputer sekarang semakin membutuhkan aplikasi yang spesifik. Di sisi lain, telah berkembang berbagai macam sistem operasi yang free dan open source maupun yang komersial dan mahal. Salah satu sistem operasi free yang semakin diminati adalah Linux. Hal ini dikarenakan pengguna Linux diberi hak seluasluasnya untuk mengekplorasi kemampuan dari Linux itu sendiri. Efeknya adalah semakin banyaknya distribusi Linux yang beredar, salah satunya adalah Linux Lubuntu. Karena fleksibel ini pula maka banyak dibangun sistem Linux yang dikhususkan untuk keperluan tertentu seperti untuk kebutuhan server, desktop bahkan untuk embeded system yang ditanam di produk mobile device yang sudah banyak diimplementasikan pada perusahaan, komunitas tertentu, masyarakat umum, institusi pemerintahan dan institusi pendidikan.

Oleh karena sifat Linux yang fleksibel, maka muncul gagasan membuat distribusi Linux untuk LAMP(Linux Apache MySQL PHP) menggunakan Linux Lubuntu 14.04 amd64 (64 bit) dengan metode remastering dalam bentuk Live USB yang ditujukan sebagai sistem operasi dan dikhususkan pada lingkungan web server. Tool-tool yang digunakan adalah phpmyadmin, inkscape, dan bluefish. Dengan Live USB, user tidak perlu lagi meng-install sistem operasi tersebut karena sistem ini dijalankan melalui media flashdisk. Hasilnya, diharapkan dapat memperlancar proses kegiatan belajar mengajar di Fakultas 
Sains dan Teknologi Universitas Katolik Musi Charitas Palembang khususnya pada matakuliah Sistem Operasi, Pemrograman Basis Web I dan Pemrograman Basis Web II.

\section{LANDASAN TEORI}

\subsection{Sistem Operasi}

Sistem operasi adalah sekumpulan rutin perangkat lunak yang berada di antara program aplikasi dan perangkat keras. Sistem operasi mempunyai dua tugas utama, yaitu [1]:

a. Pengelola seluruh sumber daya sistem komputer.

Mengelola seluruh sumber daya yang terdapat pada sistem komputer agar beroperasi secara benar dan efisien.

b. Sistem operasi sebagai penyedia layanan.

Sistem operasi menyediakan sekumpulan layanan ke pemakai sehingga memudahkan dan menyamankan penggunaan atau pemanfaatan sumber daya sistem komputer.

\subsection{Linux}

Linux adalah sistem operasi yang bersifat open source. Linux sebenarnya turunan dari UNIX yang dirancang untuk dijalankan pada personal komputer. UNIX merupakan sistem operasi yang bersifat portable (tidak bergantung pada hardware tertentu) sehingga dapat digunakan dari platform notebook hingga super-computer [2].

Saat ini, Linux adalah sistem turunan UNIX yang lengkap, dapat digunakan untuk jaringan, pengembangan perangkat lunak dan bahkan untuk penggunaan sehari-hari. Linux sekarang merupakan alternatif sistem operasi yang jauh lebih murah jika dibandingkan dengan sistem operasi komersial, dengan kemampuan Linux yang setara bahkan lebih lingkungan sistem operasi ini termasuk ratusan program termasuk kompiler, interpreter, editor dan utilitas perangkat bantu yang mendukung konektifitas, Ethernet, SLIP dan PPP, dan interoperabilitas.

Untuk masalah penggunaannya, pengguna dapat memilih distro-distro Linux yang telah dikenal, misalkan Redhat, Mandrake, Suse, Debian, Gentoo, Slackware, dan lain-lain. Perbedaan antara satu distro yang satu dengan yang lainnya adalah lebih kepada masalah program-program yang disertakan dan fungsionalitas pemakaiannya, akan tetapi tetap menggunakan kernel sama yang masih dikembangkan oleh Linus bersama komunitas programmer [3].

\subsection{Distribusi Linux}

Linux bisa didapatkan dalam berbagai distribusi (sering disebut Distro). Distro adalah bundel dari kernel Linux, beserta sistem dasar linux, program instalasi, tools basic, dan program-program lain yang bermanfaat sesuai dengan tujuan pembuatan distro. Ada banyak sekali distro Linux, diantaranya :

a) RedHat, distribusi yang paling populer, minimal di Indonesia. RedHat merupakan distro pertama yang instalasi dan pengoperasiannya mudah.

b) Debian, distro yang mengutamakan kestabilan dan kehandalan, meskipun mengorbankan aspek kemudahan dan kemutakhiran program. Debian menggunakan .deb dalam paket instalasi programnya.

c) Slackware, merupakan distro yang pernah merajai di dunia Linux. Hampir semua dokumentasi Linux disusun berdasarkan Slackware. Dua hal penting dari Slackware adalah bahwa semua isinya (kernel, library ataupun aplikasinya) adalah yang sudah teruji. Sehingga mungkin agak tua tapi yang pasti stabil. Yang kedua karena menganjurkan untuk meng-install dari source sehingga setiap program yang di install teroptimasi dengan sistem. Ini alasannya mengapa tidak mau untuk menggunakan binary RPM dan sampai Slackware 4.0 tetap menggunakan libc5 bukan glibc2 seperti yang lain.

d) SuSE, distro yang sangat terkenal dengan YaST (Yet another Setup Tools) untuk mengkonfigurasi sistem. SuSE merupakan distro pertama dimana instalasi-nya dapat menggunakan bahasa Indonesia.

e) Mandrake, merupakan varian distro RedHat yang dioptimasi untuk pentium. Kalau komputer pengguna menggunakan pentium ke atas, umumnya Linux bisa jalan lebih cepat dengan Mandrake. 
f) WinLinux, distro yang dirancang untuk di-install di atas partisi DOS (Windows). Jadi untuk menjalankannya bisa diklik dari Windows. WinLinux dibuat seakan-akan merupakan suatu program aplikasi under Windows.

Dan masih banyak distro-distro lainnya yang telah tersedia maupun yang akan muncul [4].

\subsection{Linux Lubuntu}

Lubuntu adalah sebuah proyek yang dimaksud untuk menghasilkan suatu turunan resmi yang lebih ringan dari sistem operasi Ubuntu, lebih sedikit menggunakan sumber daya dan efisien energy. Lubuntu menggunakan lingkungan desktop LXDE (Lightweight x11 Desktop Environment). Kata Lubuntu sendiri berasal dari kata LXDE dan Ubuntu, sedangkan Ubuntu sendiri berasal dari filosofi dari Afrika Selatan yang berarti "kemanusiaan kepada sesama". Adapun tujuan dari distribusi Linux Ubuntu adalah membawa semangat yang terkandung didalam filosofi Ubuntu kedalam dunia perangkat Lunak [5].

\subsection{Remastering}

Remastering adalah cara pembuatan distro Linux dengan cara membuat master distro yang baru dengan menurunkan dari distro mayor kedalam distro baru yang spesifik tujuannya [6]. Dengan remastering memungkinkan pengguna untuk menambah atau mengurangi paket aplikasi di sistem operasi Linux dengan paket aplikasi yang baru. Latar belakang dari remastering Linux adalah karena Linux induk yang ada belum bisa memenuhi kebutuhan penggunanya [2].

\subsection{Apache}

Apache adalah sebuah nama web server yang bertanggung jawab pada request-response HTTP dan logging informasi secara detail. Selain itu, Apache juga diartikan sebagai suatu web server yang kompak, modular, mengikuti standar protokol HTTP, dan tentu saja sangat digemari [7].

Pengembangannya yang dimulai dari tahun 1995 oleh sekelompok kecil pemrogram, yaitu Apache Software Foundation Incorporated, tahun 1999 mulai berkonsentrasi untuk mendukung projek Apache HTTP Server. Dengan berbasis jumlah pengguna lebih dari 25 juta server di seluruh dunia, membuat Apache HTTP Server mempunyai keunggulan dari sisi fleksibilitas dan performansi. Untuk fitur lain yang ditawarkan, adalah [3] :

a) Tingkat stabilitas yang tinggi.

b) Aplikasi secara keseluruhan, dan modul-modul tambahan bersifat open source dengan masingmasing lisensi dari setiap aplikasi.

c) Bekerja pada berbagai macam platform arsitektur dan sistem operasi.

d) Menghadirkan tingkat keamanan yang lebih baik.

e) Dapat diintergrasikan dengan berbagai modul seperti PHP, MySQL yang dapat menambah fungsionalitas dari web server.

\subsection{MySql}

MySQL merupakan salah satu database kelas dunia yang sangat cocok bila dipadukan dengan bahasa pemrograman PHP. MySQL bekerja menggunakan bahasa SQL (Structure Query Language) yang merupakan bahasa standar yang digunakan untuk manipulasi database [8].

\section{$2.8 \quad P H P$}

Hypertext Preprocessor adalah akronim untuk PHP, yang artinya adalah terdapat sebuah halaman yang aktif pada sebuah server. Halaman yang dimaksud adalah sebuah file dengan extension .php dan server yang dimaksud adalah sebuah komputer yang di dalamnya terdapat web server yang aktif. Web server akan meng-interpreter file-file PHP, sehingga perintah kode PHP tidak akan pernah dapat diketahui client hanya hasilnya saja yang akan sampai ke komputer client [3]. PHP merupakan bahasa standar yang digunakan dalam dunia web site. PHP adalah bahasa program yang berbentuk script yang diletakkan di dalam server web [9]. 


\section{METODE PENELITIAN}

Metode dalam mengembangkan suatu distro Linux dalam bentuk Live USB yang dapat digunakan sebagai sistem operasi dan web server pada Fakultas Sains dan Teknologi Universitas Katolik Musi Charitas Palembang dengan menggunakan metode remastering. Lebih jelasnya bisa dilihat bagan alir penelitian secara umum yang ditunjukkan pada Gambar 1.

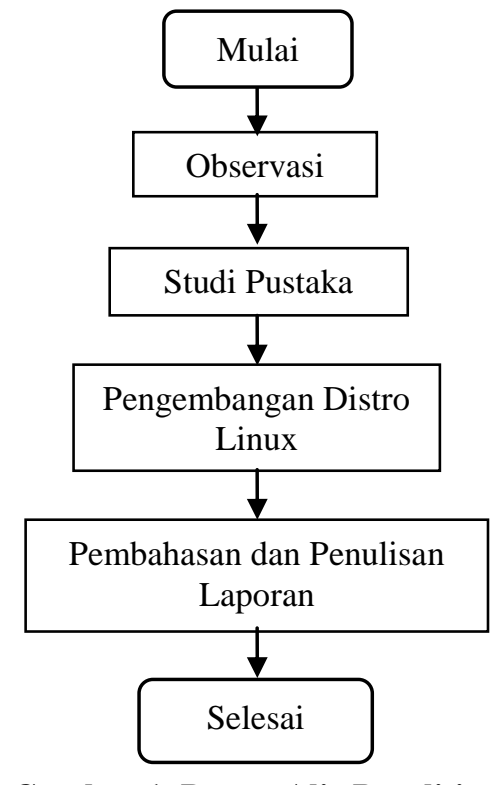

Gambar 1. Bagan Alir Penelitian

\subsection{Bahan Dan Peralatan Remastering}

Sebelum melakukan remastering, terlebih dahulu menyiapkan bahan dan peralatan yang dibutuhkan. Bahan dan peralatannya adalah sebagai berikut :

1. CD Lubuntu versi 14.04 amd64.

2. Kernel dengan modul squashfs enabled. Tetapi terlebih dahulu harus meng-install Lubuntu 14.04 amd64 ke komputer.

3. Menginstal squashfs-tools.

4. DVD Repository Ubuntu 14.04 amd64.

\subsection{Paket Aplikasi}

Penginstalan paket-paket aplikasi dilakukan melalui DVD Repository Ubuntu 14.04 amd64 yang terdiri dari 15 keping DVD. Aplikasi-aplikasi yang akan di-instal adalah aplikasi-aplikasi yang berkaitan dengan web server. Berikut adalah paket-paket aplikasi yang akan dimasukkan dalam remastering :

a) Apache2 sebagai web server.

b) Php5 sebagai web script program.

c) Mysql sebagai database server.

d) Bluefish sebagai editor HTML, PHP, CSS dan XML.

e) PhpMyAdmin sebagai administrasi database MySQL.

f) Inkscape sebagai pengolah grafik vector yang memenuhi standar XML, SVG dan CSS.

g) Gimp sebagai pengolah grafis.

\subsection{Tahap Remastering}

Jika semua bahan dan peralatan sudah tersedia, kemudian membuka terminal. Untuk kemudahan di buatkan direktori berikut :

1. cdrom, untuk tempat mengkopi isi file live $\mathrm{cd}$.

2. temp, untuk tempat me-mount file filesystem.squashfs.

3. work, untuk tempat bekerja sampai live usb siap di buat iso kembali. 
4. repo, untuk tempat menyimpan DVD Repository berbentuk file iso.

Semua direktori diatas terletak di direktori /home/username. Tahap-tahapnya yang dilakukan adalah sebagai berikut :

1. Menyiapkan direktori-direktori cdrom, temp, work dan repo.

2. Me-mount cdrom file live cd.

3. Mengkopi semua isi file live cd ke direktori cdrom.

4. Meng-unmount cdrom file live cd.

5. Membuat filesystem virtual dalam bentuk file.

6. Me-mount file filesystem.squashfs di temp dan liveusb.ext4 ke work lalu meng-copy isi temp ke work.

7. Memodifikasi dan konfigurasi sistem.

8. Mempersiapkan pemaketan kembali.

9. Meng-update daftar aplikasi yang baru.

10. Membuat file squashfs dari hasil remastering.

11. Membuat file iso tetapi sebelumnya meng-generate md5sum yang baru.

12. Membuat file iso dalam bentuk live usb.

\section{HASIL DAN PEMBAHASAN}

\subsection{Implementasi Tampilan Bootscreen}

Disini penulis memodifikasi plymouth themes Lubuntu yang secara teknis semua themes berada di directory /lib/plymouth/themes, untuk Lubuntu themes sendiri berada di directory /lib/plymouth/themes/lubuntu-logo, didalam directory tersebut terdapat bebarapa file yang akan di-edit dan ada yang tetap seperti semula. File yang peneliti edit adalah lubuntu_logo.png, dengan cara mengganti gambar baru tetapi nama file tetap seperti semula dan hasilnya seperti pada gambar 2 .

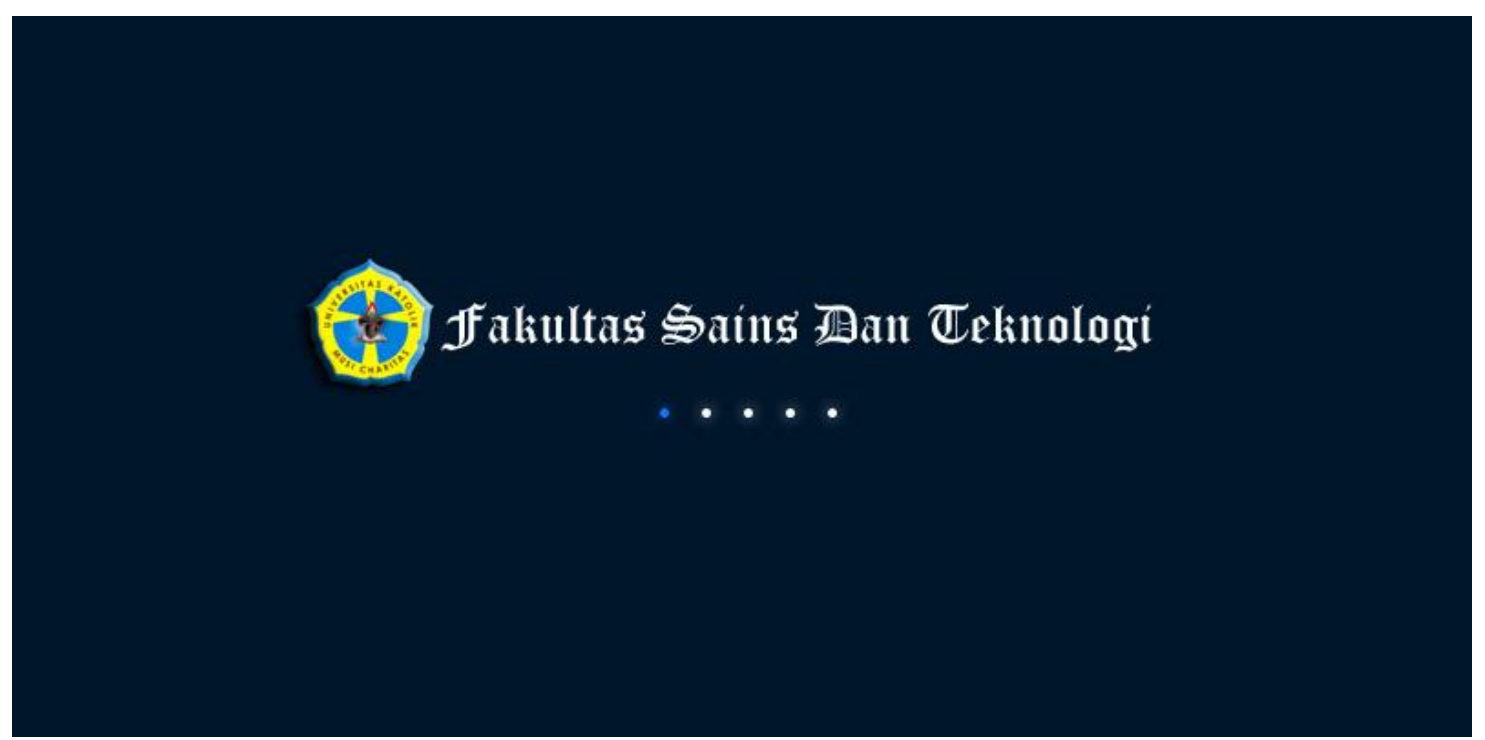

Gambar 2. Tampilan Bootscreen

\subsection{Implementasi Tampilan Desktop}

Dalam merubah tampilan desktop, penulis hanya mengganti gambarnya menggunakan gimp tetapi nama dan ektensinya tetap seperti default Linux Lubuntu, dimana letak gambar tersebut di directory /usr/share/lubuntu/wallpapers/. Gambar 3 berikut adalah tampilan awal ketika user masuk ke sistem. 


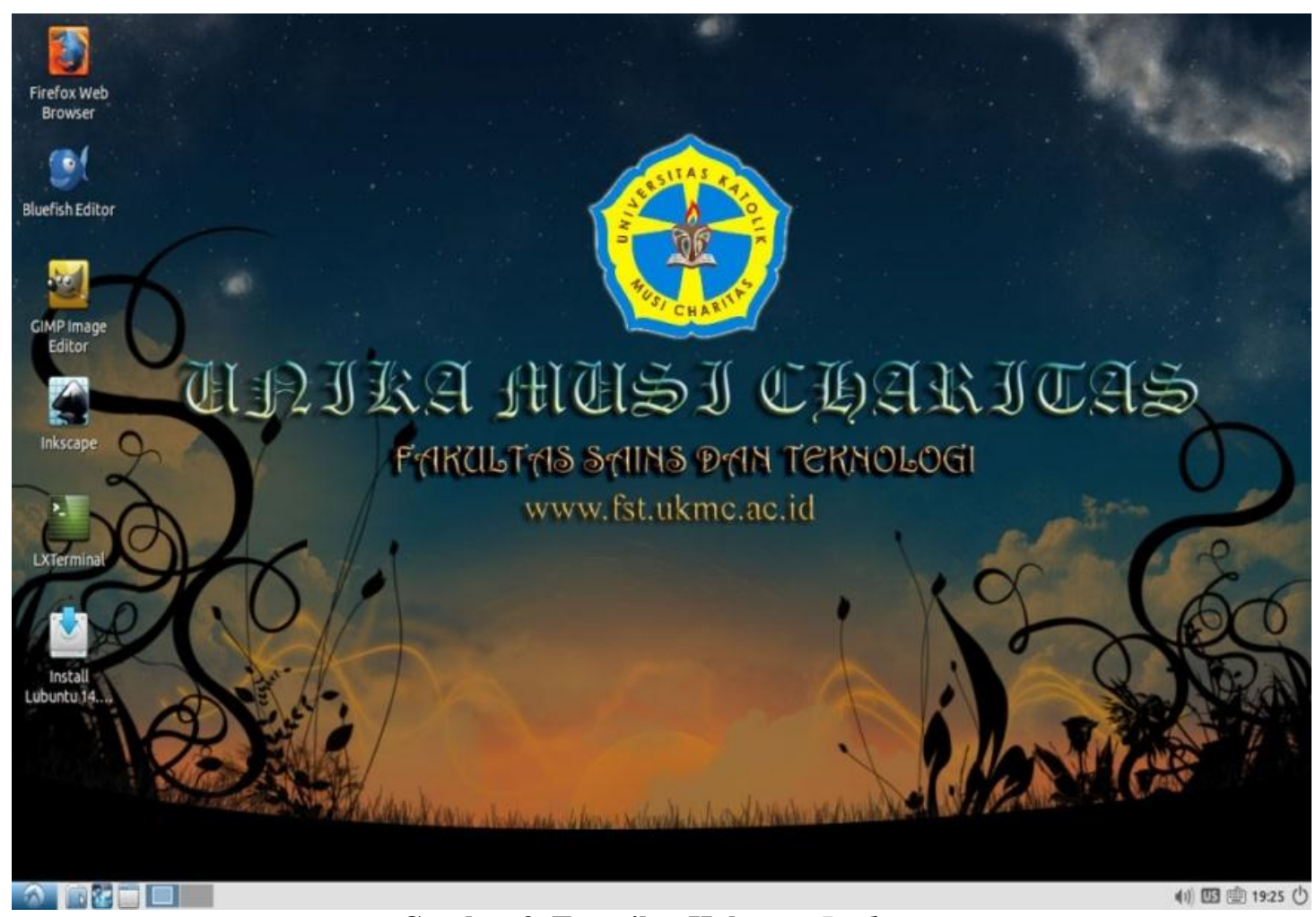

Gambar 3. Tampilan Halaman Desktop

\subsection{Implementasi Tampilan Localhost}

Cara menampilkan tampilan localhost dengan memanggil alamat lokal dari web browser seperti mozilla firefox dengan mengetikkan di address bar yakni localhost. Dimana, pada halaman localhost terdapat beberapa tutorial, yaitu belajar HTML dan CSS, belajar PHP dan belajar phpmyadmin. Tampilan halaman localhost terlihat pada gambar 4.
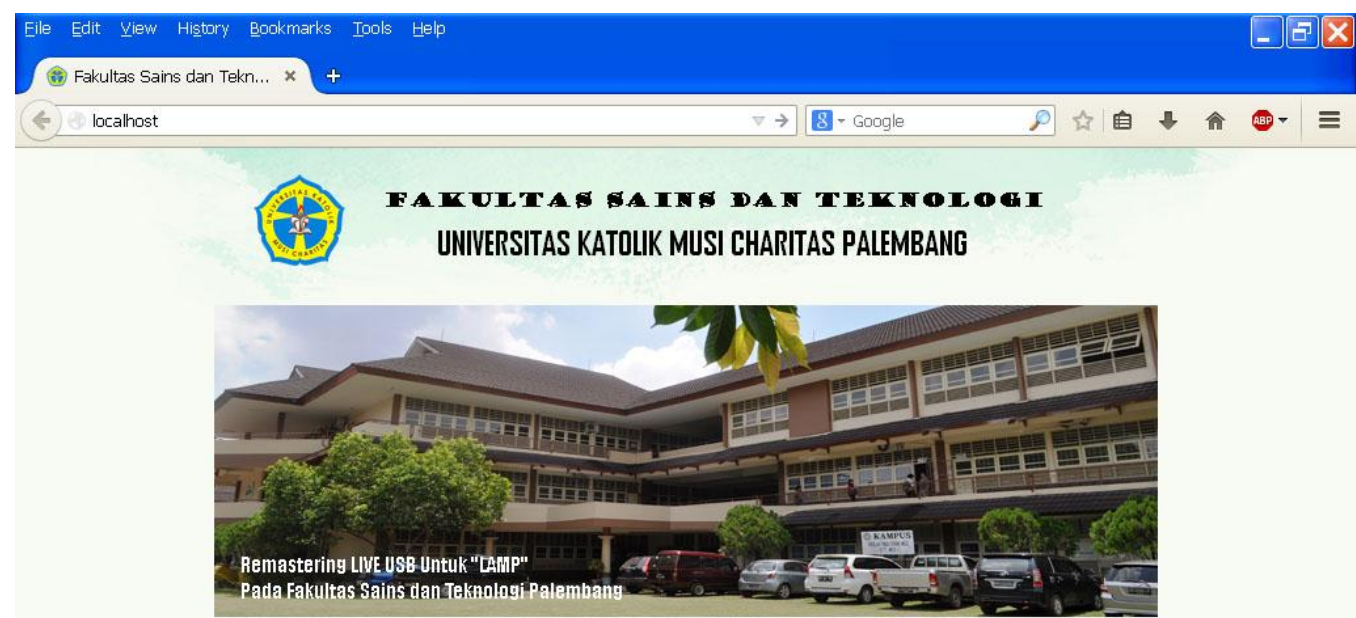

\section{Bagaimana menjadi seorang Web Developer ?}

\begin{tabular}{|c|c|c|}
\hline $\begin{array}{l}\text { Belajar HTHLL dan GSS } \\
\text { Pelajari terlebih dahulu apa itu } \\
\text { HTML dan CSS, bagaimana } \\
\text { cara pembuatan dan } \\
\text { penggabungan file HTML \& } \\
\text { CSS, fungsi tag HTML dan } \\
\text { properti CSS yang ada }\end{array}$ & $\begin{array}{l}\text { Belajar PHP } \\
\text { Pelajari apa itu PHP, hubungan } \\
\text { antara PHP dengan HTML } \\
\text { maupun MySQL, bagaimana } \\
\text { cara penggunaan PHP untuk } \\
\text { menyimpan data ke database }\end{array}$ & $\begin{array}{l}\text { Belajar Phphlitydimin } \\
\text { Pelajari apa itu PhpMyAdmin } \\
\text { cara pengoperasian } \\
\text { phpMyAdmin hubungan } \\
\text { antara PhpMyAdmin dengan } \\
\text { MySQL dan PHP. Setelah itu } \\
\text { siap membuat suatu web. }\end{array}$ \\
\hline & MySOL & \\
\hline
\end{tabular}

Gambar 4. Tampilan Localhost 


\subsection{Pengujian}

Sistem ini sudah dilakukan pengujian di beberapa komputer (desktop dan notebook), namun pengujian utama dilakukan di komputer pengembangan. Komputer pengembangan adalah komputer dimana sistem ini dibuat. Untuk menguji sistem ini, langkah-langkah yang dilakukan adalah sebagai berikut :

a) Men-setting komputer agar booting melalui media flashdisk.

b) Setelah proses booting selesai, maka user berhasil login ke dalam sistem dan secara default akan masuk ke halaman desktop.

\section{KESIMPULAN}

Dari uraian yang telah disampaikan sebelumnya, dapat diambil kesimpulan sebagai berikut :

1) Lubuntu adalah distro yang free yang dijalankan pada Live USB yang bisa menjadi solusi dari sistem operasi illegal yang sekarang banyak dipakai.

2) Distribusi Linux Lubuntu berhasil dikembangkan sebagai sistem operasi dan web server dengan tool-tool yang mempermudah user dalam menggunakannya khususnya pada proses kegiatan belajar mengajar di Fakultas Sains dan Teknologi Universitas Katolik Musi Charitas Palembang.

3) Lubuntu digunakan untuk desktop dengan aplikasi yang ringan, dimana dengan Lubuntu ini bisa dijalankan pada komputer sekelas Pentium III dengan Ram 512 MB.

\section{DAFTAR PUSTAKA}

[1] Hariyanto, Bambang., (2012). Sistem Operasi Revisi Kelima. Bandung : Informatika Bandung.

[2] Amunawar, Andreas. 2010. Membuat Distro Linux “ANDROS” (Linux Edisi Pemrograman), Jurusan D3 Teknik Informatika, STMIK AMIKOM Yogyakarta, (Online), (http://journal.amikom.ac.id/index.php/D3TI/article/view/4903, di akses pada tanggal 14 oktober 2014).

[3] Handaya, Wilfridus Bambang Triadi., et al. (2008). Linux System Administrator. Bandung : Informatika Bandung.

[4] Raharja, R. Anton., Yunianto, Afri. Widyantoro, Wisesa. Wiryana, I Made. 2001. Pengenalan Linux, Gunadarma, Jakarta, (Online), (http://idkf.bogor.net/idkf-wireless/aplikasi/linux/linux-dasarsingle.pdf, diakses tanggal 7 Januari 2015).

[5] Aprinal, Heru., 2014. Pengembangan Distribusi Sistem Operasi Linux SIWAH Untuk Keamanan Sistem Informasi Komputer Pada Universitas UBUDIYAH Indonesia, Program Studi S1 Teknik Informatika, Fakultas Ilmu Komputer, Universitas U'BUDIYAH Indonesia Banda Aceh, (Online), (http://180.241.122.205:32/index.php?jurnal=10111021\&id_prodi=7, di akses pada tanggal 14 oktober 2014).

[6] Wijaya, Andreas Setya., Hartomo, Kristoko Dwi. and Rukmasari, Amelia. 2012. "Pembuatan Distro Linux Edukasi untuk Anak-Anak Sekolah Dasar Dalam Proses Pengenalan Operating System Open Source dengan Metode Remastering”, Jurnal Teknologi Informasi-Aiti 9. 1, 1 - 100.

[7] Silitonga, Jeckson., Suswaini, Eka., Kurniawan, Hendra. Pendaftaran Mahasiswa Baru Berbasis Mobile (Studi Kasus : Universitas Maritim Raja Ali Haji). Teknik perangkat Lunak, Fakultas Teknik, Universitas Maritim Raja Ali Haji, Riau, (Online), (http://jurnal.umrah.ac.id/?p=457, di akses pada tanggal 14 oktober 2014).

[8] Saputra, Agus,. (2012). Webtips : PHP, HTML 5 dan CSS 3. Jasakom. 
Jurnal SIMETRIS, Vol 6 No 2 November 2015

ISSN: 2252-4983

[9] Nugroho, Bunafit,. (2004). PHP \& MySQL dengan Editor Dreamweaver MX. Yogyakarta : Andi. 